\title{
Observed-predicted length of stay for an acute psychiatric department, as an indicator of inpatient care inefficiencies. Retrospective case-series study. Rosa E Jiménez*1, Rosa M Lam², Milagros Marot $^{3}$ and Ariel Delgado ${ }^{4}$
}

Address: " "Hermanos Ameijeiras" General Hospital. Research and Projects Department. San Lázaro 701, Centro Habana 10300, Ciudad Habana. CUBA, ${ }^{2}$ Hematology and Immunology Institute. Calzada de Aldabó y Calle E, La Habana, Boyeros, 10800, Ciudad Habana. CUBA, 3 "Hermanos Ameijeiras" General Hospital. Psychiatric Department. San Lázaro 701, Centro Habana 10300, Ciudad Habana. CUBA and ${ }^{4}$ Ariel Delgado. Statistics Department, Province Health Division, Matanzas, CUBA

Email: Rosa E Jiménez* - rjimenez@infomed.sld.cu; Rosa M Lam - r.maria@hemato.sld.cu; Milagros Marot - psiq@hha.sld.cu; Ariel Delgado - ariel.delgado@infomed.sld.cu

* Corresponding author

Published: 17 February 2004

BMC Health Services Research 2004, 4:4

This article is available from: http://www.biomedcentral.com/l472-6963/4/4

(c) 2004 Jiménez et al; licensee BioMed Central Ltd. This is an Open Access article: verbatim copying and redistribution of this article are permitted in all media for any purpose, provided this notice is preserved along with the article's original URL.

\begin{abstract}
Background: Length of stay (LOS) is an important indicator of efficiency for inpatient care but it does not achieve an adequate performance if it is not adjusted for the case mix of the patients hospitalized during the period considered. After two similar studies for Internal Medicine and Surgery respectively, the aims of the present study were to search for Length of Stay (LOS) predictors in an acute psychiatric department and to assess the performance of the difference: observed-predicted length of stay, as an indicator of inpatient care inefficiencies.
\end{abstract}

Methods: Retrospective case-series of patients discharged during 1999 from the Psychiatric Department from General Hospital "Hermanos Ameijeiras" in Havana, Cuba. The 374 eligible medical records were randomly split into two groups of 187 each. We derived the function for estimating the predicted LOS within the first group. Possible predictors were: age; sex; place of residence; diagnosis, use of electroconvulsive therapy; co morbidities; symptoms at admission, medications, marital status, and response to treatment. LOS was the dependent variable. A thorough exam of the patients' records was the basis to assess the capacity of the function for detecting inefficiency problems, within the second group.

Results: The function explained $37 \%$ of LOS variation. The strongest influence on LOS came from: age $(p=0.002)$, response to treatment $(p<0.0001)$, the dummy for personality disorders $(p=$ $0.01)$, ECT therapy $(p=0.003)$, factor for sexual and/or eating symptoms $(p=0.003)$ and factor for psychotic symptoms $(p=0.025)$. Mean observed LOS is 2 days higher than predicted for the group of records with inefficient care, whereas for the group with acceptable efficiency, observed mean LOS was 4 days lower than predicted. The area under the ROC curve for detecting inefficiencies was $69 \%$

Conclusions: This study demonstrates the importance of possible predictors of LOS, in an acute care Psychiatric department. The proposed indicator can be readily used to detect inefficiencies. 


\section{Background}

Today there is a growing interest in improving quality and efficiency of health care to the maximum, a fact which highlights the necessity of good indicators of quality and efficiency of health care.

Length of stay (LOS) has been repeatedly used as an indicator of efficiency for inpatient care, probably due to its clear meaning as one of the main sources of hospital costs and because LOS can be also deemed an indicator of quality [1-3]. However, LOS for a certain period and facility, is not a useful basis for meaningful comparisons unless it is adjusted for the case mix of patients hospitalized during the period considered. This process is called "risk adjustment" and is thoroughly described and discussed in the book edited by Iezzoni [4].

Allegedly the ideal way of adjustment should be based on the difference between LOS a patient should require-provided the attention received was efficient-, predicted LOS, and the actual one, observed LOS. As a continuous variable, LOS (or a proper transformation) may be modeled by means of a linear regression approach [5]. If an adequate model is found, the difference between observed LOS (OLOS) and predicted LOS (PLOS) could be a proper efficiency indicator. We already evaluated such an indicator for Internal Medicine and Surgery departments with fair results [6].

As a matter of fact, several studies, some of them recently performed, have looked for LOS predictors in psychiatric departments with similar aims [7-19].

Diagnosis, severity of illness, age, sex, physical co morbidities, treatment issues and psychosocial characteristics have been already confirmed as LOS determinants with more or less strength across the above referred studies.

The present work entails two related and successive aims. Firstly, the search for an appropriate function to predict the optimal LOS for an inpatient in an acute psychiatric ward, according to his or her characteristics, and, secondly, explore the ability of the difference Observed-Predicted LOS to detect inefficient care.

\section{Methods}

The study is basically a retrospective case-series study. It is mainly descriptive although some hypothesis testing has been performed during the derivation of the function.

\section{Setting}

Information was collected from the clinical records of patients discharged from the Psychiatric Department in "Hermanos Ameijeiras" General Hospital in Havana, during 1999. The hospital is a government funded and public facility, it provides secondary and tertiary medical attention within all clinical and surgical specialities for adults except Obstetrics. The Psychiatry department comprises 46 beds, seven of which are reserved for a one week anti alcoholic addiction treatment. The remaining 39 beds are used for regular hospitalized patients admitted from three sources: 1) outpatient attention in the hospital, 2) the outpatient facilities within the hospital's catchment area or 3) the emergency department in the hospital.

\section{Data retrieval}

Included records belonged to new patients or known psychiatric patients in an acute phase of their illness. Excluded records were from: 3 self requested discharges, 2 patients included in research protocols affecting LOS, 2 patients transferred from other hospitals, 4 patients admitted for alcoholism treatment with pre-established LOS, 4 not concluded for unknown reasons (possibly self requests not stated), 2 patients escaped from the ward, and 2 patients in which the final main diagnosis was not psychiatric. For 20 patients who had more than one admission within the period only the last one was considered.

The 374 clinical records left available for our study were split randomly into two groups of 187 each. The first group was employed to derive the optimal function to estimate LOS. In the second group, we evaluated the capacity of the function to detect inefficiency problems during their stay. Thus, in both groups we obtained information from each patient record about the following variables allegedly affecting LOS: age, sex; place of residence, marital status, main diagnosis, administered medications, use of electroconvulsive therapy, co morbidities, response to treatment and symptoms at admission. Symptoms were included to account for the patient's severity of illness at admission since there is no regular Severity Index recorded for patients in this Department. Categories of all the variables, except symptoms, are displayed and detailed in Table 1 . The list of all symptoms and their categories are displayed in Table 2. LOS was expressed in days from admission to discharge.

\section{Data for validation}

In the second group each record was thoroughly examined looking for sources of inefficient care that could be retrieved from the record, namely delays due to: a) more than 2 days between the indication and the realization of laboratory tests, b) more than 4 days between the realization of laboratory tests and results return from the corresponding laboratory, c) more than 2 days between admission and diagnosis discussion (a feature of all clinical records in the hospital that should be done within 48 hours after admission), d) more than 2 days for interconsultations with another specialist within the hospital, e) 
Table I: Distribution of patients and length of stay summaries for different variable categories.

\begin{tabular}{|c|c|c|c|c|c|c|}
\hline Variables & Categories & $N$ & $\%$ & Mean LOS & Std. Deviation & Median LOS \\
\hline \multirow[t]{2}{*}{ Gender } & Male & 154 & 41.2 & 22.58 & 10.73 & 22.0 \\
\hline & Female & 220 & 58.8 & 25.16 & 10.76 & 24.0 \\
\hline \multirow[t]{3}{*}{ Age group (years) } & Less than 30 & 66 & 17.6 & 22.92 & 10.57 & 21.5 \\
\hline & 30 to 55 & 176 & 47.1 & 22.90 & 11.75 & 22 \\
\hline & Over 55 & 132 & 35.3 & 26.30 & 9.24 & 25 \\
\hline \multirow[t]{5}{*}{ Diagnostic categories } & Mood disorders & 127 & 33.9 & 25.98 & 9.59 & 25 \\
\hline & Psychotic disorders & 72 & 19.3 & 22.90 & 11.83 & 22 \\
\hline & Personality disorders & 70 & 18.7 & 22.90 & 8.85 & 22 \\
\hline & Adjustment disorders & 43 & 11.5 & 19.91 & 6.84 & 19 \\
\hline & Other disorders & 62 & 16.6 & 25.92 & 14.65 & 23.5 \\
\hline \multirow[t]{2}{*}{ Response to treatment } & immediate & 272 & 72.7 & 21.90 & 10.46 & 21 \\
\hline & delayed & 102 & 27.3 & 29.97 & 9.50 & 28 \\
\hline \multirow{2}{*}{$\begin{array}{l}\text { Electroconvulsive therapy } \\
\text { (ECT) }\end{array}$} & no & 339 & 90.6 & 23.24 & 10.45 & 22 \\
\hline & yes & 35 & 9.4 & 32.46 & 10.84 & 32 \\
\hline \multirow[t]{4}{*}{ Place of residence } & Old or Center Havana & 97 & 25.9 & 25.64 & 12.50 & 24 \\
\hline & $\begin{array}{c}\text { Another municipality in } \\
\text { Havana City }\end{array}$ & 187 & 50.0 & 23.83 & 10.83 & 22 \\
\hline & Havana province & 32 & 8.6 & 24.84 & 7.56 & 24 \\
\hline & Another province & 58 & 15.5 & 21.98 & 8.86 & 21.5 \\
\hline \multirow[t]{2}{*}{ Marital status } & with stable couple & 172 & 46.0 & 23.91 & 11.70 & 22.5 \\
\hline & no couple & 202 & 54.0 & 24.27 & 10.02 & 22 \\
\hline \multirow[t]{3}{*}{ Drugs } & None & 104 & 27.8 & 23.45 & 11.45 & 21 \\
\hline & $\begin{array}{l}\text { Antidepressants, under } \\
150 \mathrm{mg} \text { daily }\end{array}$ & 126 & 33.7 & 24.41 & 9.28 & 24 \\
\hline & Antipsychotics & 144 & 38.5 & 24.30 & $11.6 \mid$ & 22 \\
\hline \multirow[t]{3}{*}{ Co morbidities } & None & 184 & 49.2 & 22.77 & 9.15 & 22 \\
\hline & Systemic co-morbidity & 106 & 28.3 & 24.96 & 10.85 & 23.5 \\
\hline & Other co-morbidity & 84 & 22.5 & 25.94 & 13.55 & 22.5 \\
\hline Total' & - & 374 & 100.0 & 25.10 & 10.81 & 22 \\
\hline
\end{tabular}

I Total number of patients selected for the study.

Table 2: Psychiatric symptoms and syndromes considered for Principal Component Analysis

\begin{tabular}{ll}
\hline Considered as present (I) or absent (0): & $\begin{array}{l}\text { Considered in three categories: (0) no impairment, } \\
(I) \text { light impairment, (2) moderate to severe impairment. }\end{array}$ \\
\hline - Delirious ideation & - Disordered processing and interpretation of sensory information \\
- Obsessive ideation & - Thought origin impairment \\
- Suicidal ideation & - Thought process impairment \\
- Any emotional disorder & - Judgment impairment \\
- Any conation disorder (poor motivation) & - Language difficulties \\
- Signs of psychomotor agitation & - Consciousness impairment \\
- Sexual and gender identity disorders & - Orientation \\
- Any sleep disorder & - Attention-deficit/hyperactivity disorder \\
- Any eating disorder & \\
- Hygienic habits disorder & \\
- Any memory impairment &
\end{tabular}

more than 3 weekend leaves and e) more than 4 days for prescribed leaves. Records were then classified as: reflecting acceptable efficient care if none of the mentioned situa- tions were found in the record, or otherwise as care with efficiency problems. This assessment and classification was made by one of the authors (RML) blindly regarding the 
Table 3: Principal components for psychiatric symptoms. Rotated component matrix'

\begin{tabular}{|c|c|c|c|c|c|c|c|c|}
\hline \multirow[b]{2}{*}{ Symptom } & \multicolumn{8}{|c|}{ Component } \\
\hline & 1 & 2 & 3 & 4 & 5 & 6 & 7 & 8 \\
\hline $\begin{array}{r}\text { Disordered processing } \\
\text { and interpretation of sensory information }\end{array}$ & 0.762 & -0.112 & -0.069 & 0.058 & 0.076 & 0.083 & 0.004 & -0.100 \\
\hline Delirious ideation & 0.719 & -0.007 & 0.114 & -0.086 & -0.013 & -0.279 & 0.081 & 0.009 \\
\hline Thought origin impairment & 0.709 & 0.129 & -0.175 & 0.121 & -0.096 & 0.121 & -0.010 & -0.068 \\
\hline Thought process impairment & 0.102 & 0.791 & 0.003 & 0.069 & 0.035 & -0.016 & -0.127 & 0.024 \\
\hline Language difficulties & -0.063 & 0.692 & -0.048 & 0.146 & -0.013 & 0.018 & 0.077 & -0.124 \\
\hline $\begin{array}{l}\text { Sexual and gender } \\
\text { identity disorders }\end{array}$ & -0.030 & -0.087 & 0.705 & 0.013 & -0.038 & -0.008 & -0.168 & -0.073 \\
\hline Any eating disorder & -0.184 & 0.293 & 0.579 & -0.197 & 0.200 & -0.055 & 0.319 & 0.035 \\
\hline Orientation & -0.068 & 0.066 & -0.017 & 0.806 & 0.041 & -0.121 & 0.225 & 0.008 \\
\hline Consciousness impairment & 0.222 & 0.192 & -0.050 & 0.589 & 0.084 & -0.008 & -0.247 & 0.132 \\
\hline Any memory impairment & -0.059 & 0.147 & 0.135 & 0.041 & 0.754 & 0.141 & 0.036 & 0.054 \\
\hline Obsessive ideation & -0.032 & 0.360 & 0.256 & -0.145 & -0.562 & 0.141 & 0.084 & 0.093 \\
\hline Psychomotor agitation & 0.079 & -0.034 & 0.211 & 0.397 & 0.024 & -0.679 & -0.040 & -0.014 \\
\hline Any sleep disorder & 0.024 & -0.052 & 0.336 & 0.066 & 0.258 & 0.597 & -0.165 & -0.168 \\
\hline Any emotional disorder & 0.110 & -0.002 & -0.059 & 0.053 & 0.014 & -0.062 & 0.826 & 0.006 \\
\hline Any conation disorder & -0.265 & -0.095 & -0.155 & 0.096 & 0.053 & -0.214 & -0.088 & 0.665 \\
\hline Suicidal ideation & 0.054 & -0.186 & 0.462 & 0.147 & -0.256 & 0.132 & 0.008 & 0.569 \\
\hline Judgment impairment & 0.415 & 0.076 & -0.031 & 0.294 & -0.286 & 0.365 & 0.088 & 0.064 \\
\hline Hygienic habits disorder & 0.224 & 0.320 & -0.161 & -0.110 & 0.358 & 0.210 & 0.193 & 0.442 \\
\hline Attention-deficit & 0.443 & 0.315 & 0.120 & $-0.05 I$ & 0.123 & -0.164 & -0.425 & 0.276 \\
\hline
\end{tabular}

I. "Varimax"rotation. Obtained with the first group of I87 records for deriving the function.

difference Observed-Predicted LOS (OLOS-PLOS). Doubts were discussed with another author (REJ) until agreement.

Predicted LOS was obtained for each patient via the function derived with the first study group and the differences OLOS-PLOS were obtained at the end of the study, when all the information was ready for statistical processing.

\section{Statistical Analysis}

The whole group of 374 records was firstly described (mean, standard deviation and median of LOS) within the categories of the different variables. With the first group of 187 records, a Multiple Linear Regression model was applied for assessing the independent influence of each variable on LOS and appraising the possibility of obtaining the predicted LOS. An initial exploration of LOS distribution in this group showed a right asymmetry suggesting the natural logarithm of LOS as the dependent variable. Principal Component Analysis was applied to reduce 19 symptoms to 8 factors that explained $61 \%$ of symptom variation (Table 3 ). The regression function was derived with the variables and the 8 factors-after a Varimax rotation-in place of symptoms [20]. Thus, the following explanatory (independent) variables were included in the function: age as quantitative; sex, marital status, response to treatment and electroconvulsive ther- apy, as binary; co morbidities, administered drugs, diagnosis and place of residence as dummy variables; and the 8 factors (principal components) accounting for symptoms at admission. The final function was thus adjusted with 185 patients (after eliminating two outliers with standardized residuals higher than 3 ) and 24 variables. A determination coefficient $\left(\mathrm{R}^{2}\right)$ of 0.374 was obtained and considered acceptable for the next step.

The estimated function was then used to obtain the predicted LOS for each patient in the second group (187 patients). We calculated for each patient in this group its score for each of the principal components with the Factor Score Coefficient Matrix obtained with the first group of records. The difference OLOS-PLOS was also obtained for each patient in this group and the association between these differences and the classification group, according to type of attention, evaluated with one way ANOVA. Finally, an ROC curve was obtained to evaluate the capacity of the new indicator (OLOS-PLOS) to detect records with inefficiency problems. The area under the curve was the global measure of the indicator performance. Statistical analysis was performed using SPSS Version 10.0.

The Ethics for Research Committee of Hospital "Hermanos Ameijeiras" approved the research protocol provided the authors maintain the confidentiality of data 
Table 4: Multiple linear regression results'. Optimum predicting function for logarithm of length of stay.

\begin{tabular}{|c|c|c|c|c|}
\hline & \multicolumn{2}{|c|}{ Unstandardized Coefficients } & \multicolumn{2}{|c|}{ Standardized Coefficients } \\
\hline & B & Std. Error & Beta & Sig \\
\hline (Constant) & 2.358 & 0.189 & & 0.000 \\
\hline DIDIAG (Mood) & -0.085 & 0.086 & -0.103 & 0.325 \\
\hline D2DIAG(Psychosis) & -0.179 & 0.102 & -0.165 & 0.082 \\
\hline D3DIAG (Personality) & -0.238 & 0.092 & -0.236 & 0.011 \\
\hline D4DIAG (Adjustment) ${ }^{2}$ & -0.157 & 0.102 & -0.141 & 0.125 \\
\hline Age & 0.007 & 0.002 & 0.254 & 0.002 \\
\hline Gender ( $I$ : male, 2 : female) & 0.029 & 0.056 & 0.037 & 0.605 \\
\hline DIPR(Centre and Old Havana) & -0.017 & 0.082 & -0.020 & 0.836 \\
\hline D2PR(Other municipalities in Havana) & -0.074 & 0.077 & -0.093 & 0.339 \\
\hline D3PR (Havana Province) $)^{3}$ & 0.097 & 0.100 & 0.077 & 0.332 \\
\hline Marital Status & 0.093 & 0.055 & 0.118 & 0.095 \\
\hline DoDR(None) & 0.051 & 0.073 & 0.058 & 0.481 \\
\hline DIDR (Ant depressive drugs $\leq 150 \mathrm{mg})^{4}$ & 0.109 & 0.071 & 0.132 & 0.125 \\
\hline Electroconvulsive therapy & 0.267 & 0.088 & 0.215 & 0.003 \\
\hline DOCOM(None) & -0.030 & 0.070 & -0.037 & 0.674 \\
\hline DICOM (Systemic diseases) ${ }^{5}$ & 0.010 & 0.076 & 0.012 & 0.891 \\
\hline Response to Treatment & 0.230 & 0.064 & 0.246 & 0.000 \\
\hline Factor score 16 & 0.069 & 0.031 & 0.174 & 0.025 \\
\hline Factor score 2 & 0.051 & 0.027 & 0.128 & 0.059 \\
\hline Factor score 3 & 0.080 & 0.026 & 0.203 & 0.003 \\
\hline Factor score 4 & -0.019 & 0.026 & -0.048 & 0.461 \\
\hline Factor score 5 & -0.013 & 0.026 & -0.032 & 0.626 \\
\hline Factor score 6 & 0.018 & 0.027 & 0.046 & 0.504 \\
\hline Factor score 7 & 0.0009 & 0.026 & 0.002 & 0.974 \\
\hline Factor score 8 & 0.029 & 0.027 & 0.074 & 0.282 \\
\hline
\end{tabular}

I. Obtained with the first group of 185 histories after eliminating 2 outliers. 2. Dummies for diagnosis. Reference category is Rest of diagnosis. 3. Dummies for place of residence. Reference category is another province. 4. Dummies for drugs. Reference category is Antipsychotic agents 5. Dummies for co morbidities. Reference category is Other co morbidity 6. Factor scores for each of the 8 principal components. See Table 2. Model Summary: $R=0.61 \mathrm{I} ; \mathrm{R}$ Square $=0.374$

retrieved from clinical records. Only two of the authors (RML and MM, both medical doctors) worked directly with the records. The identity of the patients could not be identified in the database for statistical analysis.

\section{Results \\ Sample description}

Table 1 shows the main description of all variables in the whole group of medical records. The number of patients is fairly high for all categories. Higher mean LOS was found for patients receiving ECT during their stay and those with a delayed response to treatment.

\section{Symptoms principal components}

Table 3 displays the rotated component matrix for the symptoms. Each number in the table represents the correlation between the particular symptom and the rotated factor. Though it is not the aim of the study to deepen into the internal structure of the group of symptoms, it can be considered a fine factor solution since each symptom is only highly correlated with one of the factors. Factors are also easy to interpret since each factor correlates highly to one, two or three symptoms. Eight factors account for $61 \%$ of the variation of 19 original symptoms, a fact considered satisfactory.

\section{Multiple Linear Regression results}

Table 4 displays the results of the definitive multiple linear regression model which explains $37.4 \%$ of LOS variation in the sample. Residual analysis showed a Normal distribution and no need for quadratic terms. According to standardized regression coefficients (SRC) and statistical significance, the strongest influence on LOS came from six variables: age $(S R C=0.254)$, response to treatment ( $S R C=0.246)$, the dummy for personality disorders (SRC $=-0.236)$, ECT therapy $(\mathrm{SRC}=0.215)$, factor 3 , sexual and eating disorders $(\mathrm{SRC}=0.203$ ) and factor 1 . psychotic symptoms $($ SRC $=0.174)$. The coefficients for the dummy variables standing for diagnoses indicate adjusted mean LOS for patients with a diagnosis of a personality disorder is the lowest and adjusted mean LOS for those included in 
Table 5: Mean differences OLOS-PLOS' according to efficiency of care

\begin{tabular}{|c|c|c|c|c|}
\hline Efficiency assessment & Mean & $\mathrm{N}$ & Std. Deviation & $95 \%$ Confidence interval \\
\hline Adequate & -4.1663 & 143 & 8.0234 & -5.49 to -2.84 \\
\hline Impaired Efficiency & 2.0541 & 44 & 10.0399 & -1.00 to 5.11 \\
\hline Total & -2.7027 & 187 & 8.9134 & \\
\hline
\end{tabular}

I Obtained with the second group of 187 histories.

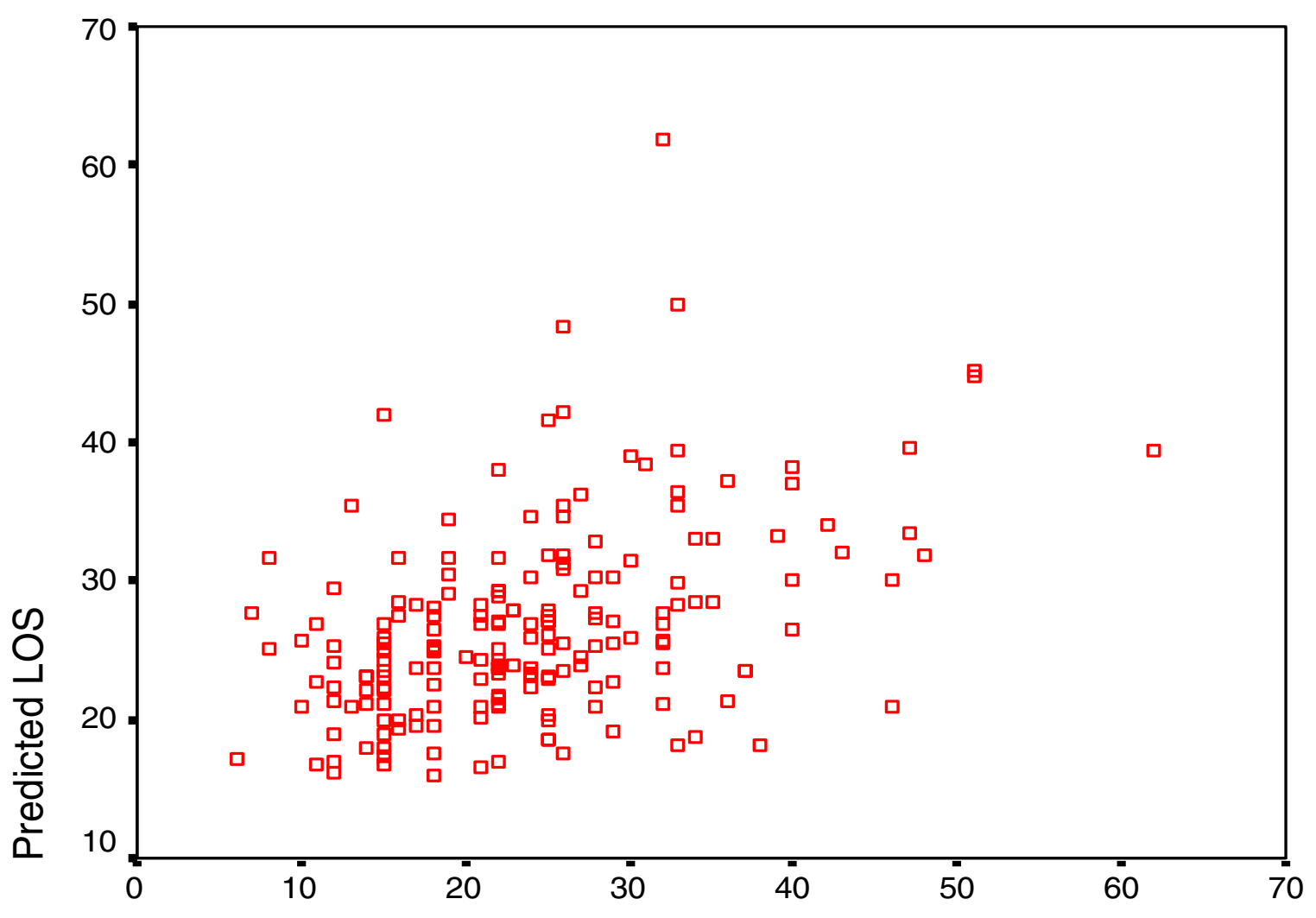

\section{Observed LOS}

Figure I

Relationship between observed and predicted LOS. Scatter diagram.

the category of other disorders (reference category) is the highest. Thus, it is not possible to identify the specific diagnosis with the largest adjusted LOS in our series.

\section{Validation}

Table 5 shows means and standard deviations of the indicator (OLOS-PLOS) for both groups of medical attention according to efficiency. In the group with efficient care observed LOS is in average 4 days lower than predicted meanwhile in the group with efficiency problems observed LOS is in average 2 days higher than predicted. Figure 1 provides a general view of the expected positive relation between observed and predicted LOS; however, it 
Table 6: Sensitivity, specificity and predictive values' for different cut-off points in the indicator OLOS-PLOS.

\begin{tabular}{|c|c|c|c|c|}
\hline $\begin{array}{l}\text { Positive if greater than or } \\
\text { equal to }\end{array}$ & Sensitivity & Specificity & Positive predictive value ${ }^{2}$ & Negative predictive value $^{2}$ \\
\hline-12 & 0.977 & 0.133 & 0.262 & 0.948 \\
\hline-11 & 0.932 & 0.161 & 0.260 & 0.882 \\
\hline-10 & 0.932 & 0.203 & 0.270 & 0.904 \\
\hline-9 & 0.932 & 0.273 & 0.288 & 0.927 \\
\hline-8 & 0.886 & 0.301 & 0.286 & 0.893 \\
\hline-7 & 0.818 & 0.350 & 0.284 & 0.859 \\
\hline-6 & 0.795 & 0.406 & 0.297 & 0.862 \\
\hline-5 & 0.727 & 0.427 & 0.286 & 0.832 \\
\hline-4 & 0.727 & 0.503 & 0.316 & 0.854 \\
\hline-3 & 0.705 & 0.552 & 0.332 & 0.856 \\
\hline-2 & 0.659 & 0.622 & 0.355 & 0.852 \\
\hline-1 & 0.591 & 0.685 & 0.372 & $0.84 I$ \\
\hline 0 & 0.591 & 0.699 & 0.383 & 0.844 \\
\hline I & 0.500 & 0.769 & 0.406 & 0.830 \\
\hline 2 & 0.455 & 0.797 & $0.4 \mid 4$ & 0.822 \\
\hline 3 & 0.409 & 0.825 & 0.425 & 0.816 \\
\hline 4 & 0.386 & 0.839 & 0.431 & 0.812 \\
\hline 5 & 0.364 & 0.874 & 0.477 & 0.813 \\
\hline 6 & $0.34 I$ & 0.909 & 0.542 & 0.814 \\
\hline 7 & 0.318 & 0.951 & 0.672 & 0.815 \\
\hline 8 & 0.250 & 0.951 & 0.617 & 0.801 \\
\hline 9 & 0.250 & 0.965 & 0.693 & 0.803 \\
\hline 10 & 0.250 & 0.972 & 0.738 & 0.804 \\
\hline
\end{tabular}

I For detecting inefficiencies. 2 Prevalence (a priori probability) of presenting inefficiencies $=0.24$. Observed prevalence in the sample.

is apparent from the table and the scatter diagram that some patients have an observed LOS rather high or low according to their predicted LOS.

Figure 2 shows the ROC Curve for detecting inefficient care with the indicator. The area under the curve is 0.695 . $(95 \% \mathrm{CI}=0.603-0.786)$.

Table 6 shows sensitivity and specificity, as well as predictive values for different cut-off points of the indicator. A reasonably high specificity $(87 \%)$ will be obtained with a cut-off point of 5 days, and a high sensitivity with a cut-off point of -6 days $(80 \%)$. There is no optimal cut-off point with high sensitivity and specificity. With a prevalence of $24 \%$ for records with inefficient care, positive predictive values are low but negative predictive values are very high for almost any point.

\section{Discussion}

Our results focus on the plausibility of obtaining a function that fairly estimates the LOS a given patient, admitted in a Psychiatric Department for acute patients, should have had according to his or her characteristics.

Age and gender relationship to psychiatric LOS have been reported in several studies $[9,12,14,16,21]$. Oiesvold et al

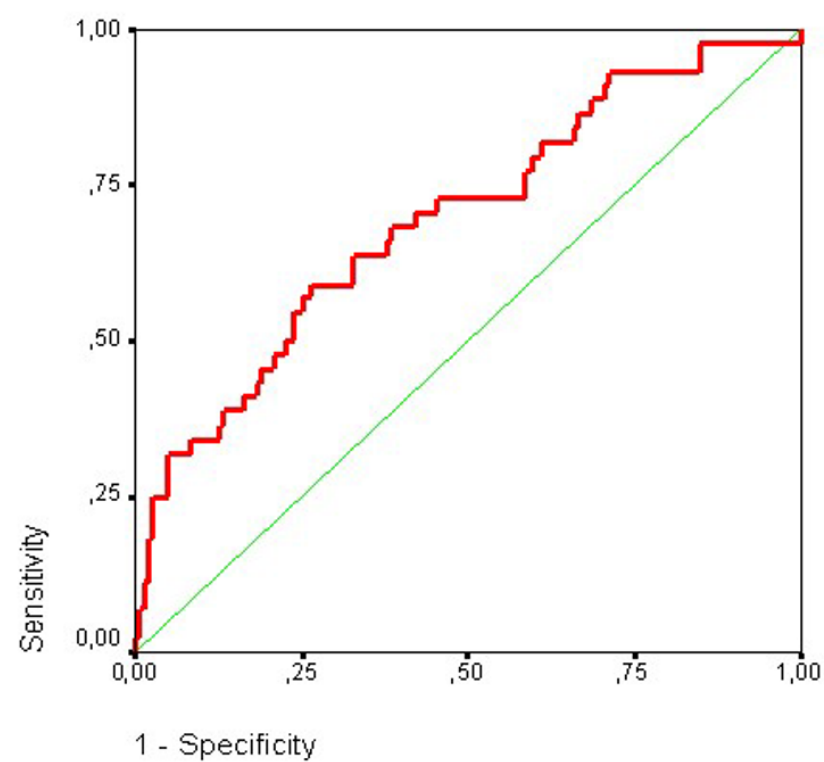

Figure 2

ROC Curve evaluating performance of OLOS-PLOS in detecting inefficiencies. Area $=0.69595 \% \mathrm{Cl}=(0.603-$ 0.787) 
[14] report longer LOS for patients in the older ages and for females in psychiatric patients in hospitals of Sweden and Finland. Huntley et al [12] classified age as one of the five variables significantly predicting LOS steadily over time. Barnow et al [9] found a correlation coefficient as high as 0.73 for describing the univariate association between age and LOS for depressed patients. Richter [21] found diagnosis and age were responsible of $10.5 \%$ of the LOS variations. Our results agree with these authors with regard to age but not to gender. Age is a natural determinant of LOS since it is closely related with all vital events; some authors (vg. Kiesler et al [7]), mix it up with another demographic variables while others like Tucker and Brems [8] just include it as a covariate.

Diagnosis is also a variable related to LOS in Psychiatric patients but how to include it with the aim of predicting LOS, is a challenge. Diagnosis Related Groups (DRG's) have been deeply explored $[7,22,23]$; they have the advantage of being just a few for Psychiatry though some authors have alleged they are not relevant for predicting LOS [24,25]. The Diagnostic and Statistical Manual of Mental Disorders (DSM) classifications (III and IV, lately) $[8,13]$ or International Classification of Diseases (ICD $9^{\text {th }}$ or $10^{\text {th }}$ [11] are also used in this context. Perhaps a broad classification system would achieve the best predictions but it would imply a huge number of patients for deriving the prediction function. We used an ad hoc classification based on DSM IV that yielded differences in LOS when analyzed univariately and when it was adjusted for other variables as well.

Most of the authors find an association between LOS and diagnosis $[11-14,26]$ but there are some discrepancies, most authors report psychoses as responsible for the highest LOS $[12,14,16]$ but others find major depression [13] as more important predictor of LOS.

It is recognized that the patient's severity of illness influence LOS independently from diagnosis $[9,17,27]$ but finding a valid, reliable and useful way to measure it, with the aim of adjusting quality indicators, has always been and continues to be a challenge [28]). Various scales for measuring severity of illness in Psychiatric inpatients have arisen in the last two decades. The Brief Psychiatric Rating Scale (BPRS) in its expanded version [29], the Psychiatric Severity of Illness Index (PSII) [27], the Computerized Psychiatric Severity Index (CPSI) [30] and the Health of the Nation Outcome Scale (HoNOS) [31,32] are probably the most mentioned ones. However, a low reliability is to expect during their use since appraisers must categorize symptoms in various levels of severity according to their opinion. Thus, implementation of any of these scales implies a period of special training and/or detailed instructions, a fact that prevents their use in daily practice.
For instance, Durbin et al [33], in an attempt to introduce CPSI for predicting LOS from clinical records, had evaluators participate in a 3 day training program.

Our principal component solution is a real possibility since we collected information from all 19 symptoms described in the psychiatric record routinely used in our wards and afterward converted them in 8 factors. However, we still had to implement 3 categories for 8 of the symptoms (see Appendix), a feature that should be changed in the near future for the sake of gaining reliability.

We have not found any other study that employs PCA to reduce dimension with the aim of predicting LOS but the method has already been used to reduce symptoms' dimension in the field of Psychiatry and Psychology [3436].

ECT was also an important LOS predictor in our series. It has been included by other authors in LOS prediction models [11] or mentioned as a cause for longer stays $[13,37]$. The use of ECT during hospitalization is a severity indicator, but is also a cause of complications.

Response to treatment turned out to be a variable with strong influence on LOS. Among reviewed literature only Draper and Luscombe [13] recognize the role of this issue in LOS prolongation. We understand it is a difficult aspect to assess and include in information systems unless the physician in charge of the patient completes the discharge form, a claim that should be evaluated in future research.

Other variables included in our study have been also explored by other authors. Marital status (or as living alone) has been acknowledged as an important LOS determinant in different studies $[10,11,13,16,17,38]$; physical co morbidities have also been analyzed $[13,33,39]$ and found fairly relevant. Place of residence, as distance from home to hospital was also included in a Brazilian study [40]; medications were also examined by Parks [10] and found "polypharmacy" as a LOS predictor in geropsychiatric patients.

About the goodness of fit of the regression function, 0.37 is not an encouraging determination coefficient but the difficulty to find functions that explain more than $50 \%$ of LOS variation, a variable of complex nature, is also true. Among the psychiatric domain, Creed et al were able to explain up to $49 \%$ of LOS variation including demographic data, clinical features, social measures and behavioural issues [11]. Richter found an R2 of only 0.11 including in its function: age, diagnosis and other clinical and sociodemographic variables [21]. Stoskopf and Horn found coefficients in the range of $0.10-0.14$ including 
only diagnosis and severity [30]. Huntley et al achieved to explain $17 \%$ of total variance in LOS including five variables in a stepwise regression analysis [12]. Regarding the fitted model, we chose the logarithmic transformation of LOS since its original distribution was right tailed. LOS distribution has been explored by various authors. Priest et al analyzed LOS distribution in an acute Psychiatric department in London; he found the exponential model yielded the best fit [41]. Stevens et al fit the exponential model and explore the influence of several factors by means of a Cox Regression model, an approach that would not allow LOS prediction [16]. However, several authors $[11,13,18]$ choose the logarithmic transformation for the search of predictors via a regression function, and perhaps most authors fit the regression model with the original LOS observations $[10,12,17,23,33]$. Marazzi in a huge European study found Lognormal, Weibull, or Gamma models were fine for describing the distribution of length of stay [42].

Regarding the proposed indicator (OLOS-PLOS), we confirmed the tendency of observed LOS to be higher than predicted LOS when there are inefficiency problems. However, we did not achieve a highly sensitive and specific cut-off point for detecting inefficiencies, a fact that emphasizes the necessity of refining the method with more variables and larger samples. A control method for efficient care similar to the proposed here is reported in some studies but not for psychiatric areas $[43,44]$.

It is fair to recognize that the process of detecting inefficiencies in the records was somewhat arbitrary; first of all we almost identify inefficiencies as delays though it could be argued inefficient care can be provided without any delay. However, it would be out of the scope of the study to search for another kind of inefficiencies, as, for instance the ones arising from a wrong management of the patient. In second place, some cut offs for deeming a record "inefficient" are also arbitrarily chosen; we chose the time intervals considered normal for the hospital usual performance in all departments. Perhaps the main limitation of the present approach is that the prediction function must be estimated in the same setting where allegedly inefficiencies exist. This handicap is partly solved with the elimination of outliers during the function development. Finally, a practical limitation of our method ensues from the many variables that must be reported by assistant physicians or retrieved from the records. We believe this issue can be solved with the introduction of computers and friendly computer programs at the wards.

\section{Conclusions}

Our work supports the importance of a series of variables as LOS predictors in a Psychiatry department. The observed-predicted length of stay can be implemented as an indicator of inefficiencies provided the appropriate cut-off point is chosen. The approach showed its validity and is adaptable to other settings although there is an obvious need to continue the effort in the search of more explanatory functions.

\section{Competing interests}

None declared.

\section{Authors' contributions}

REJ conceived the study and participated in its design and coordination. She personally wrote the manuscript. MM as the psychiatric specialist directed, organized and revised the data collected from the psychiatric records. RML directly reviewed the clinical records and obtained the information by means of adequate templates and under the supervision of MM. AD performed the statistical analysis. All authors read and approved the final manuscript

\section{Acknowledgements}

We would like to thank the Statistics Department of "Hermanos Ameijeiras" General Hospital for kindly supporting our search and review of clinical records.

\section{References}

I. Brownell MD, Roos NP: Variation in length of stay as a measure of efficiency in Manitoba hospitals. CMAJ 1995, I 52(5):675-682.

2. Chassin MR: Health Technology case study 24. Variations in Hospital Length of Stay. Their relationship to health outcomes. Washington DC, US Congress, Office of Technology Assessment 1983.

3. Bradbury RC, Golec JH, Steen PM: Linking health outcomes and resource efficiency for hospitalized patients: do physicians with low mortality and morbidity rates also have low resource expenditures? Health Serv Manage Res 2000, I3(I):57-68.

4. lezzoni LI, Ed: Risk Adjustment for measuring health care outcomes. 2nd edition. Chicago, Illinois, Health Administration Press; 1997.

5. Shwartz M, Ash AS: Evaluating the performance of Risk-Adjustment Methods: continuous outcomes. In: Risk Adjustment for measuring healthcare outcomes 2nd edition. Edited by: lezzoni LI. Chicago, Illinois, Health Administration Press; 1997:391-426.

6. Jiménez R, Domínguez E, López L, Fariñas H: Difference between observed and predicted length of stay as indicator of patient care inefficiency. Int J Qual Health Care I999, I I (5):375-84.

7. Kiesler CA, Simpkins C, Morton T: Predicting length of hospital stay for psychiatric inpatients. Hosp Community Psychiatry 1990, 4 I (2): | 49-54.

8. Tucker P, Brems C: Variables affecting length of psychiatric inpatient treatment. J Ment Health Adm 1993, 20(I):58-65.

9. Barnow S, Linden M, Schaub RT: The impact of psychosocial and clinical variables on duration of inpatient treatment for depression. Soc Psychiatry Psychiatr Epidemiol 1997, 32:312-16.

10. Parks ED, Josef N: A retrospective study of determinants of length of stay in a geropsychiatric state hospital. Psychiatr $Q$ 1997, 68(2):91-9.

II. Creed F, Tomenson B, Anthony P, Tramner M: Predicting length of stay in Psychiatry. Psychol Med 1997, 27(4):961-966.

12. Huntley DA, Cho DW, Christman J, Csernansky JG: Predicting Length of stay in an acute psychiatric hospital. Psychiatr Serv 1998, 49(8): 1049-53.

13. Draper B, Luscombe G: Quantification of factors contributing to length of stay in an acute psychogeriatric ward. Int J Geriatr Psychiatry 1998, I3(I): I-7. 
14. Oiesvold T, Saarento O, Sytema S, Christiansen L, Gostas G, Lonnerberg O, Muus S, Sandlund M, Hansson L: The Nordic Comparative Study on Sectorized Psychiatry-length of in-patient stay. Acto Psychiatr Scand 1999, 100(3):220-8.

15. Richter D: Psychiatric inpatient length of stay. An overview of methods, influences and consequences. Fortschr Neurol Psychiatr 200I, 69(I):|9-3|.

16. Stevens A, Hammer K, Buchkremer G: A statistical model for length of psychiatric in-patient treatment and an analysis of contributing factors. Acta Psychiatr Scand 200I, I03(3):203-2II.

17. Hopko DR, Lachar D, Bailley SE, Varner RV: Assessing Predictive Factors for Extended Hospitalization at Acute Psychiatric Admission. Psychiatr Serv 200I, 52:1367-1373.

18. Hoger C, Zieger H, Presting G, Witte-Lakemann G, Specht F, Rothenberger A: Predictors of length of stay in inpatient child and adolescent psychiatry: failure to validate an evidence-based model. Eur Child Adolesc Psychiatry 2002, I I (6):28I-288.

19. Baetz M, Larson DB, Marcoux G, Bowen R, Griffin R: Canadian Psychiatric Inpatient Religious Commitment: An Association with Mental Health. Can J Psychiatry 2002, 47:159-166.

20. Jonson DA: Métodos multivariados aplicados al análisis de datos. México D.F. International Thompson Editores 2000.

21. Richter D: How significant is the comparison for length of stay in psychiatric hospitals based on diagnosis and age? Gesundheitswesen 1999, 6 I(5):227-233.

22. Phelan M, Psych MRC, McCrone P: Effectiveness of Diagnosis Related Groups in predicting psychiatric resource utilization in the UK. Psychiatr Serv 1995, 46(6):547-549.

23. Keefler J, Duder S, Lechman C: Predicting length of stay in an acute care hospital: the role of psychosocial problems. Soc Work Health Care 200I, 33(2): I-16.

24. McCrone $\mathrm{P}$, Phelan $\mathrm{M}$ : Diagnosis and length of psychiatric inpatient stay. Psychol Med 1994, 24(4): I025-30.

25. Ashcraft ML, Fries BE, Nerenz DR, Falcon SP, Srivastava SV, Lee CZ Berki SE, Errera P: A psychiatric patient classification system. An alternative to diagnosis-related groups. Med Care 1989 27(5):543-557.

26. Scheytt D, Kaiser P, Priebe S: Duration of treatment and case cost in different inpatient psychiatric facilities in Berlin. Psychiatr Prax 1996, 23(I): 10-14.

27. Horn SD, Chambers AF, Sharkey PD, Horn RA: Psychiatric severity of illness. A case mix study. Med Care 1989, 27(I):69-84.

28. lezzoni LI: Risk and Outcomes. In: Risk Adjustment for measuring health care outcomes 2 nd edition. Edited by: lezzoni LI. Chicago, Illinois, Health Administration Press; 1997:I-4I.

29. Hafkenscheid A: Reliability of a standardized and expanded Brief Psychiatric Rating Scale: a replication study. Acta Psychiatr Scand 1993, 88(5):305-310.

30. Stoskopf C, Horn SD: The Computerized Psychiatric Severity Index as a predictor of inpatient Length of Stay for Psychoses. Med Care 199I, 29(3): I79-195.

31. Wing JK, Beevor AS, Curtis RH, Park SB, Hadden S, Burns A: Health of the Nation Outcome Scales (HoNOS). Research and development. Br J Psychiatry 1998, I72: I I-18.

32. Mc Clelland R, Trimble P, Fox ML, Stevenson MR, Bell B: Validation of an outcome scale for use in adult psychiatric practice. Qual Health Care 2000, 9(2):98-105.

33. Durbin J, Goering P, Pink G, Murray M: Classifying psychiatric patients: seeking better measures. Med Care 1999 37(4):415-423.

34. Perlick DA, Rosenheck RA, Clarkin JF, Sirey JA, Raue P: Symptoms Predicting Inpatient Service Use among Patients with Bipolar Affective Disorder. Psychiatr Serv 1999, 50:806-8I2.

35. Lachar D, Bailley SE, Rhoades HM, Espadas A, Aponte M, Cowan KA, Gummattira P, Kopecky CR, Wassef A: New subscales for an anchored version of the Brief Psychiatric Rating Scale: construction, reliability, and validity in acute psychiatric admissions. Psychol Assess 200I, 13(3):384-395

36. Ronan GF, Dreer LE, Dollard KM: Measuring patient symptom change on rural psychiatry units: utility of the symptom checklist-90 revised. J Clin Psychiatry 2000, 6 I (7):493-497.

37. Herr BE, Abraham HD, Anderson W: Length of stay in a general hospital psychiatric unit. Gen Hosp Psychiatry 199|, I 3(I):68-70.

38. Jakubaschk J, Waldvogel D, Wurmle O: Differences between longstay and short-stay inpatients and estimation of length of stay. A prospective study. Soc Psychiatry Psychiatr Epidemiol 1993. 28(2):84-90.

39. Sloan DM, Yokley J, Gottesman H, Schubert DS: A five-year study on the interactive effects of depression and physical illness on psychiatric unit length of stay. Psychosom Med 1999, 6I (I):2I-25.

40. Dalgalarrondo P, Gattaz WF: A psychiatric unit in a general hospital in Brazil: predictors of length of stay. Soc Psychiatr Epidemiology 1992, 27(3): |47-I50.

4I. Priest RG, Fineberg N, Myerson S, Korean T: Length of stay of acute psychiatric inpatients: an exponential model. Act Psychiatry Scand 1995, 92(4):3I5-3I7.

42. Marissa A, Packard F, Ruffle C, Beguine C: Fitting the distributions of length of stay by parametric models. Med Care 1998 , 36(6):9|5-927.

43. Best WR, Cowper DC: The ratio of observed-to-expected mortality as a quality of care indicator in non-surgical VA patients. Med Care 1994, 32(4):390-400.

44. Hartz AJ, Bade PF, Sigmann P, Guse C, Epple P, Goldberg KC: The evaluation of screening methods to identify medically unnecessary hospital stay for patients with pneumonia. Int J Qual Health Care 1996, 8:3-II.

\section{Pre-publication history}

The pre-publication history for this paper can be accessed here:

http://www.biomedcentral.com/1472-6963/4/4/prepub

Publish with BioMed Central and every scientist can read your work free of charge

"BioMed Central will be the most significant development for disseminating the results of biomedical research in our lifetime. "

Sir Paul Nurse, Cancer Research UK

Your research papers will be:

- available free of charge to the entire biomedical community

- peer reviewed and published immediately upon acceptance

- cited in PubMed and archived on PubMed Central

- yours - you keep the copyright
BioMedcentral 